\title{
Subjective impact of osteoarthritis flare-ups on patients' quality of
} life

\author{
Giuseppina Majani*1, Anna Giardini ${ }^{1}$ and Aurelio Scotti ${ }^{2}$
}

Address: ${ }^{1}$ Psychology Unit, Fondazione S. Maugeri, Clinica del Lavoro e della Riabilitazione, IRCCS, Istituto Scientifico di Montescano (PV), Italy and ${ }^{2}$ Scientific Department, Italfarmaco SpA, Milan, Italy

Email: Giuseppina Majani* - gmajani@fsm.it; Anna Giardini - agiardini@fsm.it; Aurelio Scotti - a.scotti@italfarmaco.com

* Corresponding author

Published: 16 March 2005

Health and Quality of Life Outcomes 2005, 3:14 doi:10.1 186/1477-7525-3-14

This article is available from: http://www.hqlo.com/content/3/I/l4

(c) 2005 Majani et al; licensee BioMed Central Ltd.

This is an Open Access article distributed under the terms of the Creative Commons Attribution License (http://creativecommons.org/licenses/by/2.0), which permits unrestricted use, distribution, and reproduction in any medium, provided the original work is properly cited.

\begin{abstract}
Background: Clinical trials on osteoarthritis (OA) flare-ups treatment usually focus only on objective measures of health status, albeit recent literature suggestions on the importance of patients' subjectivity. Aim of the study was to evaluate the effects of $O A$ and of its different types of medical treatment(s) on Health Related Quality of Life (HRQoL) in terms of both subjective satisfaction and functional status.

Methods: An observational study on prospective data collected from the Evaluation of Quality of life in OA (EQuO) clinical trial (April 1999-November 2000) was conducted; outpatients from 70 participating centers (Orthopedy or Rheumatology Departments in Italy) with a diagnosis of OA of the hip or knee were consecutively enrolled. Patients were observed at OA flare-ups (baseline) and at follow up 4 weeks after treatment. Patients' objective and subjective HRQoL were assessed by means of the SF-36 and the Satisfaction Profile (SAT-P, which focuses on subjective satisfaction); Present Pain at baseline and Pain Relief at follow up were also evaluated.

Results: Among the 1323 patients, II 38 (86\%) were prescribed one drug/treatment of osteoarthritis, 169 (13\%) 2 drugs/treatments, and 16 (1\%) 3 drugs/treatments; most of treatments involved the prescription of NSAIDs; non-coxib, COX2 selective NSAIDs were prescribed in about $50 \%$ of patients. Follow-up visits were performed after 29.0 days on average ( \pm 7.69 SD). For all SF-36 domains, all SAT-P items and factors, the differences between baseline and follow up scores resulted statistically significant $(\mathrm{p}<0.00 \mathrm{I})$, enlighting an improvement both in health status and in subjective HRQoL.

Conclusion: Besides the classic health status measures, the assessment of patients' subjective satisfaction provides important clues on treatments efficacy of OA within the patient-centered medicine model. In clinical practice this could lead to a better doctor-patient communication and to higher levels of treatment adherence.
\end{abstract}

\section{Background}

The impact of osteoarthritis (OA) on patient's functional levels is well known [1-3]. Pain and physical limitations constitute difficulties patients have to deal with $[4,5]$ and require long term pharmacological treatment and physical therapies. 
Usually OA affects elderly people, and is one of the main causes of physical disability. In OA patients, Health Related Quality of Life (HRQOL) and activities of daily living are negatively affected. Significant work disability, reduced ability to deal with household duties and sleep disorders are reported in patients with symptoms of OA flare-ups, together with dysfunctions in the areas of ambulation, body-care and movement (in terms of perceived health status), and emotional behaviour (in terms of perceived psychological functioning) $[1,2,4-8]$.

As a chronic condition, the impact of OA has been studied mainly focusing on its consequences on health status. Similarly, treatment efficacy is assessed within the context of health status and/or symptomatology in many clinical trials $[6,7,9-12]$. However, health status and symptomatology can be considered only two components of HRQoL [13] and little is known about the impact of OA and its treatments on patient's subjective perspective, in spite of increasing attention on this topic [14-19].

In literature, HRQoL refers to patients' appraisals of their current levels of functioning and satisfaction, compared to what they perceive to be ideal [20]. HRQoL assessment allows a subject to express his or her ability to perform daily activities across many domains which include physical, social and cognitive functioning, role activities and emotional wellbeing. Besides, "...how a subject feels about the performace of each of those activities may be assessed separately by measuring satisfaction for each domain." [21]. The subjective implications of HRQoL, within the context of patient centred medicine, have been already stressed by suggestions from recent reliable scientific literature [15,17-24].

The aim of the present study is to evaluate the effects of OA and of its different types of medical treatment(s) on HRQoL in terms of both subjective satisfaction and functional status.

\section{Methods}

\section{Patient population and procedure}

Data from collaborating, educated outpatients aged 5080 years with a diagnosis of OA of the hip or knee according to the criteria of the American College of Rheumatology [25] were collected in this observational, prospective study.

Outpatients $(\mathrm{n}=1340)$ were consecutively enrolled in 70 Italian participating centers (Orthopedy or Rheumatology Departments, listed in Appendix A [see additional file]) from April 1999 to November 2000. 147 patients withdrawn OA treatment before follow-up visit.
All patients signed an informed consent in which the purposes of the study (HRQoL assessment and treatment efficacy, as primary and secondary outcomes respectively) were clearly stated. Approval for this research was obtained by the ethics committee, patients did not receive any remuneration for their participation.

Patients with concomitant osteoarticular disorders, impairment of motor function not due to OA of the hip or knee, concomitant systemic disease(s) affecting HRQoL or requiring NSAIDs/steroids use on a regular basis were not included into the study, in order to avoid biases in the results due to treatments other than OA treatments.

Patients were observed at OA flare-ups, when attending for a visit (baseline) and at follow up 4 weeks after treatment. According to the observational design of this trial, no "study treatments" were assigned to patients, but any $\operatorname{drug}(\mathrm{s}) /$ medical treatment(s) considered by the physician as adequate to the patient's clinical condition was freely prescribed; therefore patients were not previously randomized to treatment.

During both visits, patients were administered the following: the Visual Analogue Scale (VAS) [26] on Present Pain (baseline) or on Pain Relief (follow up); the Medical Outcomes Study Short-Form 36 Health Status Survey (SF-36) [27] in its validated Italian version $[28,29]$ and the Satisfaction Profile (SAT-P) [30].

Moreover, at follow up, the global assessments of efficacy and tolerability of the medical treatment(s) prescribed for OA flare ups (expressed by the patient and by the physician according to a 4 point semi-quantitative rating scale: excellent - good - moderate - poor) were collected. Side effects to this/these treatment(s), if any, were registered as well.

The assessment procedure was standardized for all the participating centres. During the visit patients were invited to compile alone all the questionnaires and rating scales, only if required patients were assisted by a trained health professional.

Self-reporting bias in HRQoL improvements was kept under control by the assessment procedure and by the adoption of valid and reliable questionnaires.

\section{Measures}

Visual Analogue Scale

The VAS is perhaps the most widely used instrument for the measurement of pain intensity. The classic version of the VAS was administered: 10 centimeter line, horizontal. "It is a simple, robust, sensitive, and reproducible 
instrument that enables a patient to express the severity of his pain in such a way that it can be given a numerical value." [26] Its psychometric properties and its utility in clinical trials have been confirmed $[2,8,31,32]$. VAS on Present Pain ranged from "no pain" to "the worst pain possible"; VAS on Pain Relief ranged from "no pain relief" to "the maximum pain relief". Scores ranged from 0 to 100.

\section{SF-36}

The SF-36 is a well known self-administered and generic health status measure which encompasses 8 domains related to daily life activities: physical functioning, role limitations due to physical problems, role limitations due to emotional problems, vitality, bodily pain, social functioning, mental health and general health perception [3335]. Each domain scores from 0 (lowest level of functioning) to 100 (highest level of functioning). The instrument has been extensively validated within the Medical Outcome Study [33] and in other settings [34].

\section{Satisfaction Profile}

The SAT-P is a self-administered, generic questionnaire which provides a satisfaction profile in daily life and can be considered as an indicator of subjective QoL. Satisfaction can be defined as the cognitive product of the comparison between ideal life and reality, and can therefore be quantitatively measured. The subject is asked to evaluate his/her satisfaction about 32 life aspects with reference to the last month (on $3210 \mathrm{~cm}$ horizontal VAS) independently of his/her objective health status (for example: "How satisfied have you been in the last month with your Resistance to physical fatigue?"; "How satisfied...with your Mood?"; "How satisfied...with your Emotional stability?"). It provides 32 individual scores and 5 factor scores, all ranging from 0 (lowest level of satisfaction) to 100 (highest level of satisfaction). Together with its ability to detect patient's subjective satisfaction, the SAT-P addresses some aspects of daily life which are not included in SF-36 items (i.e. sleep, sexual life, quality of couple relationship, eating, self-confidence, resistance to stress, etc.). Its psychometric properties and clinical utility have been confirmed [30,36,37].

\section{Statistical analyses}

Sociodemographic data and clinical values were analysed by means of descriptive statistics. Since the incidence of withdrawals resulted low, analyses were performed on complete cases and no solutions for handling missing data was adopted.

Baseline and follow-up of SF-36 and SAT-P item and factor scores were compared by means of Analusis of Covariance (ANCOVA). Moreover, ANCOVAs were adopted in order to evaluate the impact of clinical variables on SF-36
Table I: Patients' characteristics

\begin{tabular}{|c|c|}
\hline Gender (F/M) & $795 / 528$ \\
\hline Age (years, mean $\pm S D)$ & $64.4 \pm 10.3$ \\
\hline \multicolumn{2}{|l|}{ Marital status: } \\
\hline Single, $\mathrm{n}(\%)$ & $72(5.4)$ \\
\hline Married, n (\%) & $922(69.7)$ \\
\hline Widowed, n (\%) & $220(16.6)$ \\
\hline Separated/divorced, n (\%) & $13(1.0)$ \\
\hline Missing, $n(\%)$ & $96(7.3)$ \\
\hline \multicolumn{2}{|l|}{ Educational level: } \\
\hline Primary school, n (\%) & $548(4 I .4)$ \\
\hline Junior high school, n (\%) & $325(24.6)$ \\
\hline Senior high school, n (\%) & $280(21.2)$ \\
\hline Degree/Master/PhD, n (\%) & $103(7.7)$ \\
\hline Missing, $n(\%)$ & $67(5.1)$ \\
\hline \multicolumn{2}{|l|}{ Employment status: } \\
\hline Employed, n (\%) & $434(32.8)$ \\
\hline Retired, n (\%) & $550(41.6)$ \\
\hline Housewife, n (\%) & $288(21.8)$ \\
\hline Missing, n (\%) & $51(3.8)$ \\
\hline Body weight $(\mathrm{kg}$, mean $\pm \mathrm{SD})$ & $73.4 \pm 11.0$ \\
\hline \multicolumn{2}{|l|}{ OA localization: } \\
\hline Knee, n (\%) & $658(49.7)$ \\
\hline Hip, n (\%) & $463(35.1)$ \\
\hline Knee + hip, n (\%) & $202(15.2)$ \\
\hline VAS Present Pain (mm, mean \pm SD) & $67.7 \pm 17.0$ \\
\hline Concomitant diseases, n (\%) & $632(47.8)$ \\
\hline Concomitant treatments, $\mathrm{n}(\%)$ & $444(33.6)$ \\
\hline
\end{tabular}

and SAT-P factor delta scores (calculated subtracting the follow-up scores from baseline scores). The variables included into the models were: age, gender, body weight, OA localization (hip, knee, or both), VAS Present Pain, presence of concomitant disease(s), type of treatment (COX2 selective NSAIDs vs. other treatments). Results were summarized using mean \pm SE for continuous variables and frequency (absolute and percent) for categorical variables. All $\mathrm{p}$ values are two-tailed and $\mathrm{p}<.05$ was considered statistically significant. All computations were carried-out by resorting to SAS 8.0 procedures.

\section{Results}

Patients demographic and clinical characteristics (OA localization (hip/knee/both), VAS Present Pain, type of medical treatment(s) of OA flare-ups, concomitant diseases and treatments are shown in Table 1. Patients' baseline VAS Present Pain resulted consistent with a clinical condition of moderate to severe rheumatic disease.

The most frequent concomitant diseases were: hypertension (19.1\%), metabolic and nutritional disorders (9.2\%), muscoloskeletal, connective tissue and bone disorders $(8.2 \%)$ and gastrointestinal system disorders $(4.3 \%)$. The most frequently prescribed concomitant treatments were: cardiologic drugs $(9.7 \%)$ and antihypertensive $(9.4 \%)$, antidiabetic drugs (8.4\%), antithrombotic 
Table 2: Treatments prescribed for osteoarthritis flare-ups

\begin{tabular}{lll}
\hline & $\mathrm{n}$ & $\%$ patients \\
\hline COX2 NON-SELECTIVE NSAIDs & & 16.7 \\
Arylacetic acid derivatives (diclofenac, indomethacin, sulindac, etc.) & 12.5 \\
Arylpropionic acid derivatives (ibuprofen, naproxen, ketoprofen, etc.) & 165 & 13.7 \\
Oxycams (piroxicam, tenoxicam, etc.) & 181 & 8.1 \\
Others (nabumetone, glucosamine, diacerein, etc.) & 107 & 52.1 \\
COX2 SELECTIVE NSAIDs & 689 & 3.5 \\
Nimesulide betadex (or nimesulide) & 46 & 3.3 \\
OTHER DRUGS/TREATMENTS & 44 & 4.5 \\
Various, systemic (ASA, paracetamol, corticosteroids, centrally acting myorelaxants) & 60 \\
Various, topical (transcutaneous or intraarticular) & \\
Physical treatment (mobilization, iontophoresis, etc.) & & \\
\hline
\end{tabular}

Table 3: SF 36 scores (Mean \pm SE). Baseline vs Follow-up scores. At the ANCOVAs: $p<0.001$ for all domains

\begin{tabular}{llll}
\hline SF-36 domains & Baseline & Follow up & $\mathrm{P}$ \\
\hline Physical Functioning & $47.9 \pm 0.7$ & $59.3 \pm 0.7$ & $<.00$ I \\
Role Physical & $27.8 \pm 1.0$ & $48.0 \pm 1.1$ & $<.001$ \\
Bodily Pain & $31.7 \pm 0.4$ & $50.5 \pm 0.5$ & $<.001$ \\
General Health & $45.8 \pm 0.5$ & $50.0 \pm 0.5$ & $<.001$ \\
Vitality & $46.5 \pm 0.5$ & $53.2 \pm 0.5$ & $<.001$ \\
Social Functioning & $44.1 \pm 0.6$ & $65.4 \pm 0.6$ & $<.001$ \\
Role Emotional & $46.9 \pm 1.2$ & $65.7 \pm 1.1$ & $<.001$ \\
Mental Health & $59.2 \pm 0.5$ & $65.4 \pm 0.5$ & $<.001$
\end{tabular}

agents $(4.5 \%)$, antiacids (6.7\%), sedatives (4.8\%). 1138 patients $(86 \%)$ were prescribed one drug/treatment of OA, 169 patients (13\%) 2 drugs/treatments, and 16 patients $(1 \%)$ received 3 drugs/treatments. Most of treatments involved the prescription of NSAIDs; non-coxib, COX2 selective NSAIDs (nimesulide betadex and nimesulide, the only two COX2 selective NSAIDs available in Italy at the time of this study) were prescribed in about $50 \%$ of patients (Table 2).

Follow-up visits were performed after 29.0 days on average $( \pm 7.69$ SD). Only a small number of patients $(17$; $1.2 \%$ ) did not attend follow-up visit.

\section{HRQoL assessment: SF-36}

For all SF-36 domains, the difference between baseline and follow up scores resulted statistically significant ( $\mathrm{p}<$ 0.001) (Table 3).

Baseline Present Pain was associated with almost all the SF-36 domains (Table 4). The presence of concomitant disease(s) resulted in a statistically significant association with 4 domains: Role Physical, Bodily Pain, General Health, Social Functioning. The type of OA treatment was associated with Physical Functioning and Bodily Pain. OA localization and age was associated with only one domain: Physical Functioning and Role Physical respectively. Gender and body weight did not correlate with any SF-36 domain.

\section{HRQoL assessment: SAT-P factors}

All the differences between baseline and follow up SAT-P factor scores were statistically significant $(\mathrm{p}<0.001)$ (Table 5).

Baseline pain was significantly associated with all SAT-P factors (Table 6). The presence of concomitant disease(s) was in a statistically significant association with 3 out of 5 factors: Psychological functioning, Sleep-Eating-Leisure, Social functioning. OA treatment was associated with the factor Sleep-Eating-Leisure.

\section{HRQoL assessment: SAT-P items}

Figure 1 shows the graphic representation of baseline and follow up SAT-P item scores. All the differences were statistically significant $(\mathrm{p}<0.001)$.

\section{Clinical outcome of OA treatment: Efficacy and Tolerability}

At follow-up, mean VAS Pain Relief was $61.1 \mathrm{~mm}( \pm 24.3$ $\mathrm{SD})$.

In $65 \%$ of cases treatment efficacy was evaluated as good or excellent by patients themselves, in $67 \%$ of cases it was evaluated as good or excellent by physicians. In $81 \%$ of cases treatment tolerability was evaluated as good or excellent by patients themselves, in $84 \%$ of cases it was evaluated as good or excellent by physicians. It was evaluated as poor in $7 \%$ and $6 \%$ of cases respectively (Table 7 ). 
Table 4: Detected statistical significances on SF-36 delta scores. The p values resulted from the ANCOVAs are indicated.

\begin{tabular}{|c|c|c|c|c|c|c|c|}
\hline \multirow[t]{2}{*}{ SF-36 domains } & \multicolumn{7}{|c|}{ Covariates } \\
\hline & Age & Gender & Body weight & OA localization & Present Pain & Concomitant diseases & Treatment \\
\hline Physical Functioning & & & & 0.021 & 0.0001 & & 0.020 \\
\hline Role Physical & 0.022 & & & & & 0.007 & \\
\hline Bodily Pain & & & & & 0.0001 & 0.0001 & 0.006 \\
\hline General Health & & & & & 0.0001 & 0.003 & \\
\hline Vitality & & & & & 0.0001 & & \\
\hline Social Functioning & & & & & 0.0001 & 0.003 & \\
\hline Role Emotional & & & & & 0.007 & & \\
\hline Mental Health & & & & & 0.0001 & & \\
\hline
\end{tabular}

Table 5: SAT-P factor scores $(M \pm S E)$. Baseline vs Follow-up scores. At the ANCOVAs: $p<0.00 I$ for all Factors.

\begin{tabular}{llll}
\hline SAT-P Factors & Baseline & Follow up & $P$ \\
\hline Psychological functioning & $59.3 \pm 0.6$ & $65.5 \pm 0.5$ & $P<.001$ \\
Physical functioning & $41.3 \pm 0.5$ & $51.9 \pm 0.5$ & $P<.001$ \\
Work & $53.3 \pm 0.7$ & $57.8 \pm 0.7$ & $P<.001$ \\
Sleep/Eating/Leisure & $55.4 \pm 0.5$ & $60.9 \pm 0.5$ & $\mathrm{P}<.001$ \\
Social functioning & $66.0 \pm 0.6$ & $70.8 \pm 0.5$ & $\mathrm{P}<.001$ \\
\hline
\end{tabular}

Table 6: Detected statistical significances on SAT-P factors. The $p$ values resulted from the ANCOVAs are indicated

\begin{tabular}{|c|c|c|c|c|c|c|c|}
\hline \multirow[t]{2}{*}{ SAT-P Factors } & \multicolumn{7}{|c|}{ Covariates } \\
\hline & Age & Gender & Body weight & OA localization & Present Pain & Concomitant diseases & Treatment \\
\hline Psychological functioning & & & & & 0.0001 & 0.022 & \\
\hline Physical functioning & & & & & 0.0001 & & \\
\hline Work & & & & & 0.007 & & \\
\hline Sleep/Eating/Leisure & & & & & 0.0001 & 0.007 & 0.026 \\
\hline Social functioning & & & & & 0.0001 & 0.018 & \\
\hline
\end{tabular}

$11.1 \%$ of patients reported side effects to medical treatment of OA; most of these reactions involved the gastrointestinal system. Poor tolerability led to treatment withdrawal in $6.2 \%$ of patients.

\section{Discussion}

Our study represents, to our knowledge, the largest observational prospective clinical trial carried out in OA patients' subjective HRQoL. The sample size and the very small number of drop-outs could be considered the strenghts of the study.

A limit of the study could be considered the adoption of the SAT-P which is a new questionnaire, validated on the Italian population [30], but not previously used in clinical trials or in OA patients. Nevertheless, its psychometric properties have been previously confirmed, and moreover it is the only Italian questionnaire specifically aimed at assessing subjective satisfaction in daily life, independently of the presence of a disease. Its user friendly structure and its easily comprehensible graphical representation could be considered substantial methodological facilities both in research and in clinical practice.

Finally, the coherence between the data provided by the two HRQoL instruments could confirm that health status and subjective satisfaction partially overlap, and allows us to study the same phenomenon from two different points of view: the objective and the subjective. This could therefore be considered the added value of the study.

Considering the whole sample, SF-36 results confirm what previous studies have already enlightened in clinical trials: the SF-36 is, according to Kosinski et al. [35], a suit- 


\section{Psychological functioning}

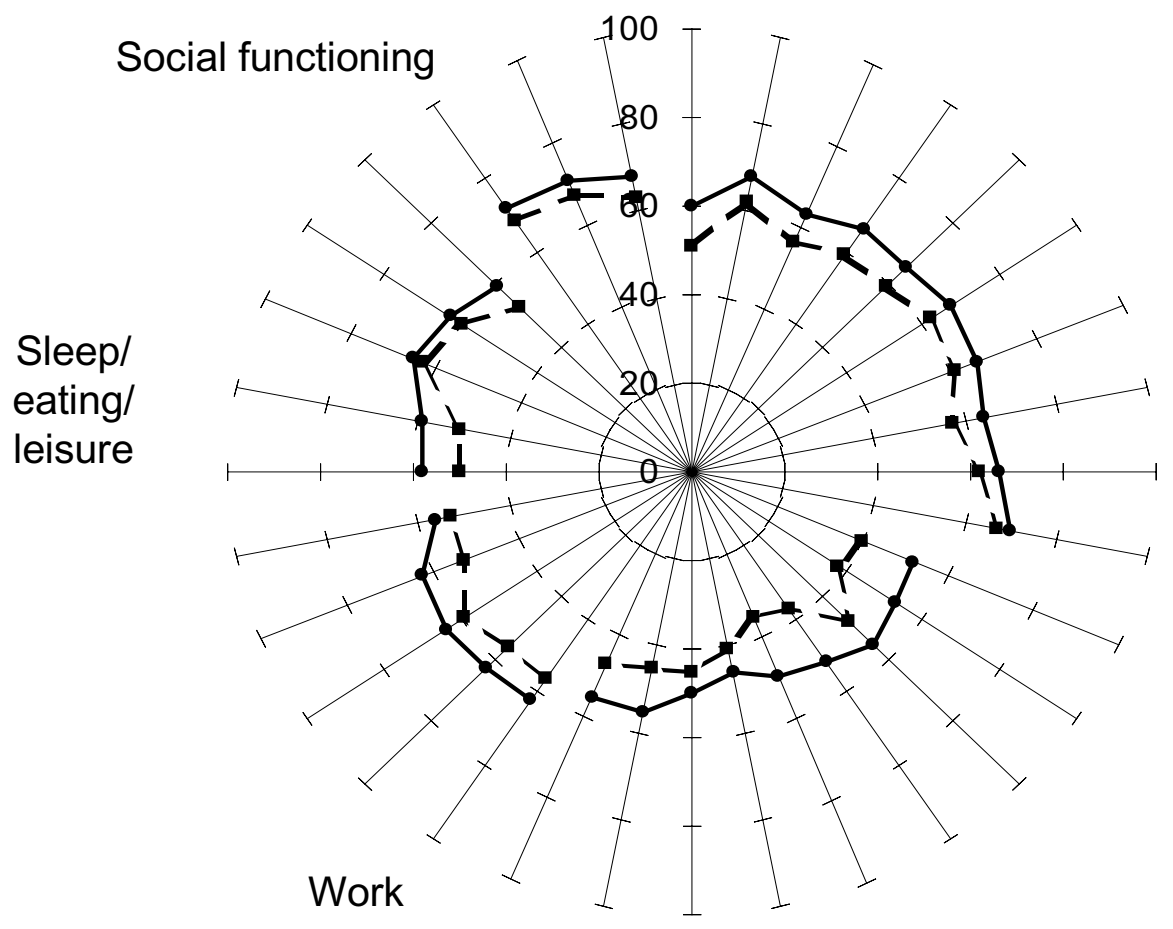

Physical functioning

- - baseline $(n=1323)$

Follow-up $(n=1323)$

Figure I

SAT-P items: mean scores at baseline and at follow-up. For all the differences (ANCOVAs) $\mathrm{p}<0.00 \mathrm{I}$.

Table 7: OA treatments' evaluations (efficacy and tolerability)

\begin{tabular}{llllll}
\hline & $\begin{array}{l}\text { Poor } \\
\mathrm{n}(\%)\end{array}$ & $\begin{array}{l}\text { Moderate } \\
\mathrm{n}(\%)\end{array}$ & $\begin{array}{l}\text { Good } \\
\mathrm{n}(\%)\end{array}$ & $\begin{array}{l}\text { Excellent } \\
\mathrm{n}(\%)\end{array}$ & $\begin{array}{l}\text { Missing data } \\
\mathrm{n}(\%)\end{array}$ \\
\hline $\begin{array}{lllll}\text { Efficacy - patients } \\
\text { Efficacy - physicians }\end{array}$ & $163(12.3)$ & $288(21.8)$ & $634(47.9)$ & $227(17.2)$ & $11(0.8)$ \\
$\begin{array}{l}\text { Tolerability - patients } \\
\begin{array}{l}\text { Tolerability - } \\
\text { Physicians }\end{array}\end{array}$ & $93(7.1)$ & $292(22.1)$ & $634(47.9)$ & $257(19.4)$ & $11(0.8)$ \\
\hline
\end{tabular}

able instrument for assessing health status in OA, and medical treatment improves functionality levels in daily life aspects.
The same conclusions could be drawn for the SAT-P: on the whole sample a general improvement of satisfaction levels can be observed in all the 32 items considered. In other words, pharmacological treatment has a significant 
positive impact on patients' both objective functioning and subjective well-being [16].

Thanks to the sinergic utility of the two instruments it has been possible to enlight results otherwise left unperceived and whose positive value on patients' life is unquestionable.

Further investigations are needed in order to better clarify the relationships between perceived pain and pain relief and patients' HRQoL. Mastery, self-efficacy and coping abilities could be significant mediators between these two constructs $[38,39]$.

\section{Conclusion}

From both an objective and a subjective point of view, OA flare-ups' treatment has proved to have positive effects on HRQoL. The sinergic use of a health status measure (SF36) and of a tool addressing subjective satisfaction (SATP) allows to wider the focus on patients' life.

This methodological approach could help clinicians and researchers in transferring into practice the ICF model issues [40], with special attention on Activity and Participation and on Environmental Factors.

\section{List of abbreviations \\ ANCOVA Analysis of Covariance}

HRQoL Health Related Quality of Life

NSAID Non Steroid Anti Inflammatory Drugs

OA Osteoarthritis

SAT -P Satisfaction Profile

SF-36 Medical Outcome Study Short-Form 36 Health Status Survey

VAS Visual Analogue Scale

\section{Competing interests}

The author AS is employee of the company that partially funded the study.

\section{Authors' contributions}

GM: responsible for the design of the study, contributed to the statistical evaluation, contributed to the writing of the paper.

AG: responsible for the statistical evaluation, contributed to the writing of the paper.
AS: contributed to the design of the study and data collection, contributed to the statistical evaluation, contributed to revise the manuscript.

\section{Additional material}

\section{Additional File 1}

Appendix A - Participating Centers

Click here for file

[http://www.biomedcentral.com/content/supplementary/1477-

7525-3-14-S1.doc]

\section{Acknowledgements}

This study has been partially funded by Italfarmaco SpA, Milan, Italy. We would gratefully acknowledge the recruitment and data collection of the many physicians and nurses who collaborated to our study (in Appendix A all the participating centers are listed [see additional file]).

\section{References}

I. de Bock GH, Kaptein AA, Touw-Otten F, Mulder JD: Healthrelated quality of life in patients with osteoarthritis in a family practice setting. Arthritis Care Res 1995, 8:88-93.

2. Hopman-Rock M, Kraaimaat FW, Bijlsma : Quality of life in elderly subjects with pain in the hip or knee. Qual Life Res 1997, 6:67-76.

3. Birrel F, Croft P, Cooper C, Hosie G, Macfarlane G, Silman A: Health impact of pain in the hip region with and without radiographic evidence of osteoathritis: a study of new attenders to primary care. Ann Rheum Dis 2000, 59:857-863.

4. Briggs A, Scott E, Steele K: Impact of osteoarthritis and analgesic treatment on quality of life of an elderly population. Ann Pharmacother 1999, 33: I 154-II59.

5. Creamer P, Lethbridge-Cejku M, Hochberg MC: Factors associated with functional impairment in symtomatic knee osteoarthritis. Rheumatology 2000, 39:490-496.

6. de Bock GH, Hermans J, van Marwijk HWJ, Kaptein AA, Mulder JD: Health-related quality of life assessments in osteoarthritis during NSAID treatment. Pharm World Sci I996, I 8: I30-I 36.

7. La Montagna G, Tirri G, Cacace E, Perprgnano G, Covelli M, Pipitone V, D'Agostino P, Magarò M, Ferraccioli G, Mascia MT, Manzini E, Minari C, Barreca C, Marcolongo R, Paresce E, Colombo B: Quality of life assessment during six months of NSAID treatment [Gonarthrosis and quality of life (GOAL) Study]. Clin Exp Rheumatol 1998, 16:49-54.

8. Wolfe F, Kong SX, Watson DJ: Gastrointestinal symptoms and health related quality of life in patients with arthritis. J Rheumatol 2000, 27:1373-1378.

9. Grace D, Rogers J, Skeith K, Anderson K: Topical diclofenac versus placebo: a double blind, randomized clinical trial in patients with osteoathritis of the knee. J Rheumatol 1999, 26:2659-2663.

10. Zhao SZ, McMillen JI, Markenson JA, Dedhiya SD, Zhao WW, Osterhaus JT, Yu SS: Evaluation of the functional status aspects of health-related quality of life of patients with osteoarthritis treated with celecoxib. Pharmacotherapy 1999, 19:1269-1278.

II. Zhao SZ, Dedhiya SD, Bocanegra TS, Fort JG, Kuss ME, Rush SM: Health-related quality-of-life effects of oxaprozin and nabumetone in patients with osteoarthritis of the knee. Clin Ther 1999, 2 I:205-217.

12. Yocum D, Fleischmann R, Dalgin P, Caldwell J, Hall D, Roszko P: Safety and efficacy of meloxicam in the treatment of osteoarthritis: a I2-week, double-blind, multiple-dose, placebocontrolled trial. Arch Intern Med 2000, I 60:2947-2954.

13. Smith KW, Avis NE, Assmann SF: Distinguishing between quality of life and health status in quality of life research: a metaanalysis. Qual Life Res 1999, 8:447-459.

14. Gill TM, Feinstein AR: A critical appraisal of the quality of quality-of-life measurements. JAMA 1994, 272:619-626. 
15. Glass RM, Editorial: The patient-physician relationship: JAMA focuses of the center of medicine. JAMA 1996, 275: I47- I48.

16. Muldoon MF, Barger SD, Flory JD, Manuck SB: What are quality of life measurements measuring? BM] 1998, 3 16:542-545.

17. Rapkin BD, Shwartz CE: Toward a theoretical model of qualityof-life appraisal: Implications of findings from studies of response shift. Health and Quality of Life Outcomes 2004, 2:14.

18. Shwartz CE, Rapkin BD: Reconsidering the psychometrics of quality of life assessment in light of response shift and appraisal. Health and Quality of Life Outcomes 2004, 2:16.

19. Asadi-Lari M, Tamburini M, Gray D: Patients' needs, satisfaction, and health related quality of life: Towards a comprehensive model. Health and Quality of Life Outcomes 2004, 2:32.

20. Cella DF, Tulsky DS: Measuring quality of life today: methodological aspects. Oncology 1990, 5:29-38.

21. Berzon RA: Understanding and using health-related quality of life instrument within clinical research studies. In Quality of Life Assessment in Clinical Trials Edited by: Staquet MJ, Hays RD, Fayers PM. New York: Oxford University Press; 1998:3-15.

22. Carr AJ, Gibson B, Robinson PG: Measuring quality of life. Is quality of life determined by expectations or experience? BMJ 200I, 322:1240-3

23. Higginsin IJ, Carr Al: Measuring quality of life. Using quality of life measures in the clinical setting. BMJ 200I, 322:1297-300.

24. Carr AJ, Higginson IJ: Measuring quality of life. Are quality of life measures patient centred? BMJ 200I, 322:1357-60.

25. Altman RD: The Classification of Osteoarthritis. Journal Rheumatology. 200I, 22(suppl 43):42-43.

26. Huskisson EC: Visual Analogue Scales. In Pain measurement and assessment Edited by: Melzack R. New York: Raven Press; 1983:33-37.

27. Ware JE Jr, Snow KK, Kosinski M, Gandek B: SF-36 Health Survey: Manual and interpretation guide Boston, Mass: The Health Institute, New England Medical Center; 1993.

28. Apolone G, Mosconi P, Ware JE Jr: Questionario sullo stato di salute SF36: manuale d'uso e guida all'interpretazione dei risultati Milano: Guerini e Associati; 1997.

29. Apolone G, Mosconi P: The Italian SF-36 Health Survey: traslation, validation and norming. J Clin Epidemiol 1998, 5 I: I025- 1036.

30. Majani G, Pierobon A, Giardini A, Callegari S: Satisfaction Profile (SAT-P) in 732 patients: focus on subjectivity in HRQoL assessment. Psychol Health 2000, 15:409-422.

31. Jensen MP, Karoly P, O'Riordan EF, Bland F Jr, Burns RS: The subjective experience of acute pain: An assessment of the utility of 10 indices. Clin J Pain 1989, 5:153-159.

32. Strong J, Ashton R, Chant D: Pain intensity measurement on chronic low back pain. Clin J Pain 1991, 7:209-218.

33. Stewart AL, Greenfield S, Hays RD, Wells K, Rogers WH, Berry SD, McGlynn EA, Ware JE Jr: Functional status and well-being of patients with chronic conditions. JAMA 1989, 262:907-913.

34. Brazier JE, Harper R, Jones NMB, O'Cathain A, Thomas KJ, Usherwood T, Westlake L: Validating the SF-36 Health Survey Questionnaire: new outcome measure for primary care. BMJ 1992, 305: $160-164$.

35. Kosinski M, Keller SD, Hatoum HT, Kong SX, Ware JE: The SF-36 Health Survey as a generic outcome measure in clinical trials of patients with osteoathritis and rheumatoid arthritis: tests of data quality, scaling assumptions and score reliability. Med Care 1999, 37(Suppl):MSI0-22.

36. Majani G, Pierobon A, Giardini A, Callegari S, Opasich C, Cobelli F, Tavazzi L: Relationship between psychological profile and cardiological variables in chronic heart failure: the role of patient subjectivity. Eur Heart J 1999, 20: I 579- I586.

37. Majani G, Baiardini I, Giardini A, Senna GE, Minale P, D'Ulisse S, Ciprandi G, Canonica GW: Health-related quality of life assessment in young adults with seasonal allergic rhinitis. Allergy 200I, 56:313-317.

38. McCracken LM: Learning to live with the pain: acceptance of pain predicts adjustment in persons with chronic pain. Pain 1998, 74:21-27.

39. Arnstein P, Caudill M, Mandle CL, Norris A, Beasley R: Self-efficacy as a mediator of the relationship between pain intensity, disability and depression in chronic pain patients. Pain 1999, 80:483-491.

40. World Health Organization: International Classification of Functioning, Disability and Health World Health Organization: Geneva; 200I.

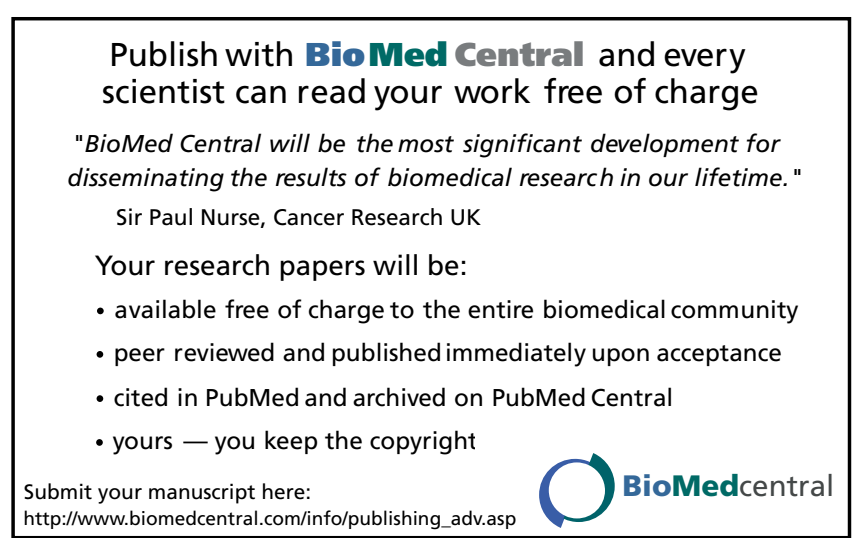

